\title{
SPECIAL FOCUS \\ Health Care System Planning for and Response to a Nuclear Detonation
}

\author{
John L. Hick, MD; David M. Weinstock, MD; C. Norman Coleman, MD; Dan Hanfling, MD; \\ Stephen Cantrill, MD; Irwin Redlener, MD; Judith L. Bader, MD, CAPT-USPHS; \\ Paula Murrain-Hill, MPH; Ann R. Knebel, DNSc, RADM-USPHS
}

\section{ABSTRACT}

The hallmark of a successful response to a nuclear detonation will be the resilience of the community, region, and nation. An incident of this magnitude will rapidly become a national incident; however, the initial critical steps to reduce lives lost, save the lives that can be saved with the resources available, and understand and apply resources available to a complex and dynamic situation will be the responsibility of the local and regional responders and planners. Expectations of the public health and health care systems will be met to the extent possible by coordination, cooperation, and an effort to produce as consistent a response as possible for the victims. Responders will face extraordinarily stressful situations, and their own physical and psychological health is of great importance to optimizing the response. This article illustrates through vignettes and supporting text how the incident may unfold for the various components of the health and medical systems and provides additional context for the discipline-related actions outlined in the state and local planners' playbook.

(Disaster Med Public Health Preparedness. 2011;5:S73-S88)

Key Words: nuclear detonation, disaster response, surge capacity

$\mathrm{H}$ istorically, detailed civilian medical planning for nuclear detonation incidents has been limited, in part related to the overwhelming nature of global thermonuclear war scenarios. Although the chances of a nuclear incident involving an improvised nuclear device are small, the impact on a city and the surrounding region would be catastrophic. Knebel et $\mathrm{al}^{1}$ provide a description of the physical aftermath and DiCarlo et $\mathrm{al}^{2}$ overview casualty medical care issues. Beyond the severe damage zone and the moderate damage zone, the physical infrastructure will be mostly intact (see Knebel et $\mathrm{al}^{1}$ ). Thus, although the incident is physically catastrophic to a limited area, preparation and response planning including sheltering, evacuation, and medical response in the affected region can help save tens of thousands of lives.

The Department of Health and Human Services (DHHS) and other agencies have scripted playbooks for a range of hazards designed to guide federal agency response. Based on discussions with local/regional planners, from participation in various national-level exercises, and from feedback on a number of DHHS products, the Scarce Resources for a Nuclear Detonation Project, in conjunction with the Office of the Assistant Secretary for Preparedness and Response, produced a prototype state and local planners' playbook for medical response to a nuclear detonation that local/regional planners could use as a template for local preparation and planning, and thus potentially harmonize concepts, plans, and terminology throughout the United States. This article provides discipline-oriented infor- mation that sets the context for the recommended actions in the playbook. ${ }^{3}$

\section{RESPONSE PRINCIPLES}

Resiliency of medical care networks is critical to successful response. 4,5 Priorities common to all-hazards response during the first hours to days include appropriate notifications, mobilization of available resources, implementation of incident command systems, information gathering to obtain situational awareness, and multiagency coordination. Key features that will affect response that are presented in other manuscripts include the following:

- Sheltering in place and efficient dissemination of accurate, essential information regarding evacuation and availability of medical assistance are extremely important. ${ }^{6}$

- Concomitant trauma, burn, and radiation injuries in the severe damage zone result in few survivors. ${ }^{2}$

- Many injured individuals will have no radiation exposure or contamination and many fallout victims will have little or no physical trauma. ${ }^{2,6,7}$

- Radiation levels decay rapidly, making perimeters and exposures dynamic for medical care, search and rescue, and evacuation. ${ }^{6}$

The initial blast will produce traumatic injury, including secondary injury from building collapse, broken glass, automobile accidents (as many as 30000 in computer models from flash blindness and other causes). ${ }^{1,6,7}$ The initial influx of victims will likely be from trauma and 
burns. Radiation casualties will occur from the initial detonation (prompt radiation) often combined with traumatic injury and many radiation-only injuries from fallout. Fallout decays rapidly, so most of the severe radiation exposure will be in the first few hours. Including time spent sheltering and for transportation, it is anticipated that the radiation victims will begin reaching emergency departments (EDs) within the first 12 hours as they self-evacuate. Because of their location, staff at some health care facilities may see almost exclusively traumatic injuries, burns, or fallout-related illness. Depending on the nature of the facility, they may be ill prepared for the burns, trauma, or types of patients - for example, injuries and exposures affecting children and/or their caregivers will place particular stress on medical response facilities that do not normally provide pediatric emergency services.

\section{Triage and Initial Trauma Care}

Although triage concepts are understood by most emergency physicians ${ }^{8}$ and practiced in limited scope at times when operative or diagnostic imaging priorities between patients need to be made, it is rare for physicians to face significant resource triage decisions ${ }^{9-11}$ or hundreds of patients presenting per hour for care. ${ }^{12} \mathrm{Lim}$ ited guidance is available for catastrophic situations. ${ }^{11,13,14}$

The degree of resource triage that will be exercised after a nuclear detonation is far different from any previous disaster in the United States. Typical mass casualty prioritization to operating rooms or computed tomography scans, in general, will be abandoned, with ratios at some hospitals of more than $1000 \mathrm{ca}-$ sualties presenting per operating room available. Providers must be trained in such events to avoid "doing what we usually do, only faster" ${ }^{15}$ and make conscious decisions to direct resources more broadly to salvageable casualties. ${ }^{10,16}$ The benefit in already having triage guidelines in place is obvious.

Hospitals within 100 to $200 \mathrm{mi}$ (one-half to a full tank of gas, roughly) can expect to receive self-referred casualties in the early aftermath of the incident, although not in as large volume as facilities who are close to ground zero. Within 24 to 72 hours of detonation, it is likely that proximal medical facilities will be resource, space, and personnel depleted, resulting in greater migration of injured, exposed, and/or highly anxious individuals into more distant locations beyond ground zero. The experience will likely parallel the aftermath of hurricanes, in which a disaster displaces a large population and destroys infrastructure. ${ }^{11,17}$ This will be an exceedingly dynamic situation. At all of the receiving hospitals, there may be varying degrees of triage of resources based on demand.

Decision making and triage for an individual will depend on the following:

- Medical condition and prognosis (initially assuming that the best care is available and then considering what the outcome will be in the scarce-resources environment, because both estimates will be important)
- Amount of resources needed to achieve the best possible outcome

- Degree of resources imbalance at the place and time that the decisions are made

- Ability to anticipate supply and demand changes-the situation may get better for an individual as time passes

- Patient's initial response to stabilization

- Victim reevaluation as the resources situation changes

Although complex, these decisions will have to be made quickly, in a chaotic environment, and with limited supporting data or diagnostics. Surgery and emergency medicine staff are likely best equipped to make triage decisions in these situations so that select patients can be prioritized for available interventions. ${ }^{18}$

For medical decision making and triage, it is necessary to have an understanding of survivability of various categories of injury, including a single injury of burn, blast, radiation, and combined injury, as discussed by DiCarlo et al elsewhere in this special issue of Disaster Medicine and Public Health Preparedness. ${ }^{2}$ It should be noted that special populations such as pediatrics may require significantly different assessment and treatment as compared with the usual adult population.

Rapid assessment of patients for severe bleeding and possible penetrating truncal injury ${ }^{19}$ is critical, because these must be addressed in the hospital environment. Patients should be met outside the facility or in lobby areas and those with minor injuries directed away from the facility to other hospitals, clinics, designated adjacent buildings, or to await medical care or assembly center opening (see Knebel et $\mathrm{al}^{1}$ and DiCarlo et $\mathrm{al}^{2}$ ). Transportation will require improvisation, including buses and selftransportation. Figure 1 outlines a potential approach to triaging patients presenting to hospitals after a nuclear detonation.

Based on military experience, aggressive hemorrhage control is the single most beneficial medical intervention in basic trauma care, ${ }^{20,21}$ and control of major external hemorrhage should be a focus in the triage area. This type of control may require pressure dressings or even use of arterial tourniquets in some cases (tourniquets are not commonly used in ED settings, but can be easily fashioned). Nonclinical staff, "the walking wounded," and patients themselves can assist with direct pressure hemorrhage control to free up clinical staff for continued triage. Internal hemorrhage control and targeted procedures, which provide the maximal patient benefit for the minimum time and resource investment (such as needle thoracostomy or chest tubes for isolated pneumo/ hemothorax, for example), should be prioritized next.

The medical response unfolds in stages (the playbook ${ }^{3}$ is also organized in this way):

1. Preincident: Preparation (possibly some ramp-up based on intelligence)

2. Phase I: Early phase: 0 to 24 hours

3. Phase II: Intermediate phase: 24 to 96 hours (in addition to ongoing 24 hours)

4. Phase III: Later phase: $>96$ hours 
The recovery phase, which begins early in the incident as displaced people and damaged infrastructure are addressed, causes enormous disruption that may last for many years. Recovery is not a subject of the Scarce Resources for a Nuclear Detonation Project and is discussed only briefly.

The following topics are presented by function and sector, including vignettes to illustrate how early event actions may unfold: emergency medical services (EMS), initial health care facility response, public health, medical system response, evacuee medical care and fallout-related radiation illness, and recovery.

\section{Emergency Medical Services}

\section{Initial EMS Actions}

Recognition that a nuclear detonation has occurred may be delayed because weather conditions can mask the brilliant flash of light and mushroom-shaped cloud. The availability of radiation detectors for vehicles, facilities, and individuals will expedite defining the incident and organizing the response. The 4 physical zones of response are described by Knebel and colleagues ${ }^{1}$ and in Planning Guidance for Response to a Nuclear Detonation. ${ }^{6}$ The incident commander (IC) ${ }^{22}$ and EMS will play a critical role in determining radiation triage, treatment, and transport (RTR) sites, some of which will form spontaneously during an incident (see Knebel et $\mathrm{al}^{1}$ and Coleman et $\mathrm{l}^{7}$ for details). Public safety answering points (911 centers) will be overwhelmed immediately, and contingency plans for public communication will help minimize panic. These plans will include information regarding shelter, evacuation and assembly points, personal decontamination, and avoidance of medical facilities by people who are not seriously injured or located within the dangerous fallout zone. ${ }^{1}$ Coordination of communication requires careful planning and execution to ensure interoperability and functionality of both the systems and the message for the public.

\section{FIGURE 1}

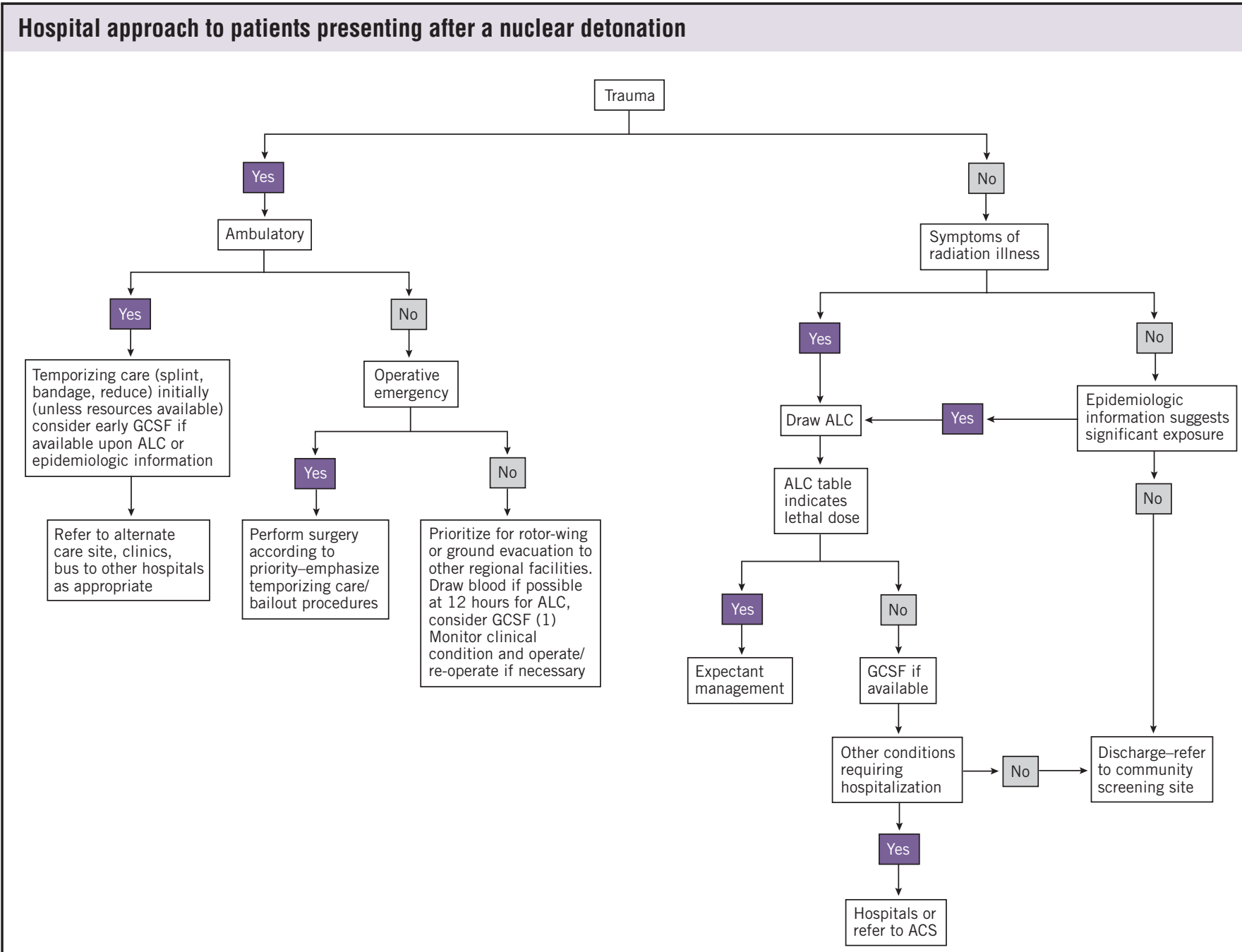

Hospital triage: assumes hospital resources are inadequate for demand but not overwhelmed. As physical radiation exposure information becomes available hours after the event, people may be triaged to not needing radiation assessment if they are not in radiation zones. Physical radiation exposure may also be used to estimate combined injury victims, although confirmatory laboratory data may be needed. Absolute lymphocyte count interpretation available on the Radiation Emergency Medical Management Web site. ${ }^{36}$ Temporizing care for severely injured victims may be palliative care only. 


\section{EMS Response Box 1: Key Principles for EMS Response to a Nuclear Detonation}

- The safety of EMS providers is paramount, including providing protective gear and radiation exposure determination and control measures.

- Radiation levels increase rapidly (greater than linearly) closer to the scene and fall off rapidly outside the severe damage (total structural collapse) zone.

- Radiation exposure rates are critical to establishing location of triage/casualty collection points (recognizing rapid decay may allow movement of these sites over time).

- Search and rescue of patients in higher radiation/damage areas is a low priority.

- Efforts should focus on people with moderate injuries in areas from the blast upwind or with minimal fallout.

- EMS uses usual trauma triage guidelines during the initial response phase.

- EMS personnel can maximize lives saved in the early aftermath of the event by providing hemorrhage control and triaging victims to available transportation to health care facilities or other patient-collection areas.

- Assistance in making victims ambulatory or ability to be helped by a "buddy system" may save many lives (eg, splinting, superficial wound bandaging) and allow self-evacuation.

- In the face of rapidly changing conditions, the triage category for a victim may improve as resources arrive. Thus, serial victim evaluation is important.

\section{EMS Response Box 2: Day 1}

Ron Jin was a paramedic staffing Medic 1 when the blast occurred. Available EMS units were directed to 2 areas on the north side of the blast zone for staging at the request of the initial units on scene. The initial EMS units had to stop far from the apparent source of the blast because of significant glass and debris in the road. They were overwhelmed there by ambulatory casualties with glass and shrapnel-type injuries. Jin and other arriving EMS personnel advanced further into the area with fire personnel who were carrying dosimeters (each captain had a digital alarm dosimeter). A casualty collection point was established at a 5 -rem/hour threshold by Jin and his colleagues, while fire personnel conducted brief "hasty searches" in damaged structures in lower radiation areas. The collection point was soon overwhelmed by "the walking wounded." Firefighters volunteered to search zones of higher radiation, but they were advised by their battalion chief to concentrate on the large numbers of moderately injured patients. Jin acted as the triage officer at the casualty collection point, directing bystanders and public safety personnel to ferry/walk casualties to the vehicle staging area for transport. Ambulatory victims were asked to walk to buses that were unable to approach closely because of debris. Those with minor injuries were encouraged to assist each other in making it to the vehicle staging area. Additional treatment supplies and narcotic analgesics arrived later as part of the preplanned EMS disaster supplies. After 45 minutes, Jin rotated his responsibility as triage officer to another EMS provider and accompanied a critical patient in the ambulance to Sacred Heart Hospital.

In addition to the usual precautions relating to physical hazards, safety of EMS personnel in a nuclear detonation requires appropriate use of radiation detectors and guidance as to radia- tion exposure limits, preferably determined before an incident. Although the IC will make the decisions, in general, limits of 5 rem (Roentgen equivalent man) annual total dose have been recommended for industrial radiation workers and up to 25 rem for lifesaving activities. ${ }^{23}$ (These levels are based on the delayed lifetime increased risk for cancer, which is about $0.05 \% /$ rem. ${ }^{24}$ ) Exposures $>25$ rem may be justified in isolated circumstances if it would save many lives, with the proper consent of the responder. It must be remembered that these are annual limits, so once certain doses are reached further activity in a radiation zone may be precluded or severely limited.

Initial EMS response follows usual incident response/mass casualty incident principles, although the incident scope will require significant plan flexibility, using physical approaches that avoid or limit radiation exposure. Access roads will require both debris clearance and law enforcement security to maintain order and flow of emergency supplies. Many of the initial casualties encountered, particularly from the light damage zone, will have little or no radiation exposure, and somewhat later, casualties from the dangerous fallout zones will have radiation exposure with little or no injury. EMS will guide or direct many victims to assembly centers or medical facilities as defined in the RTR system. ${ }^{1,3}$ Hospitals within walking distance (2-5 mi) of the incident will be completely overwhelmed with selfreferred casualties and should be bypassed by EMS if other hospitals provide equivalent service and can be accessed. ${ }^{12,25}$

Triage follows usual trauma triage principles in the immediate aftermath of a detonation. EMS agencies may use simple triage and rapid treatment (more commonly known as START), sort, assess, lifesaving interventions, triage, and/or transport (more commonly known as SALT), or other accepted triage methods, ${ }^{19,26-28}$ but they should incorporate a search for truncal-penetrating injuries, because these can appear benign but may represent severe internal injuries. ${ }^{18,19}$ Radiation triage will incorporate physical location of victim and onset time and severity of subsequent symptoms. EMS personnel should be cautious in performing radiationexposure triage by symptoms because vomiting ${ }^{29}$ and neurological symptoms are not specific to radiation injury and may represent traumatic or psychological causes. In addition, specific training, information, and medical countermeasures pertaining to the different needs of pediatric victims after a radiation incident must be available to EMS personnel. These should include plans for the stabilization, treatment, and transport of children without the explicit consent of caregivers, who may be incapacitated, deceased, or otherwise unavailable. EMS services should plan for situations in which both adult and pediatric members of a family are injured and attempt to minimize separation by transport to a single facility. Pediatric hospitals should, therefore, be prepared to accept adult casualties and the more commonly planned reverse situation.

Ambulatory victims who have fallout on them ideally should perform dry decontamination, which is removing outer garments and dusting off exposed areas such as the hair. Medical triage and trans- 
portation to safer areas should take high priority. A "buddy system" approach of victims helping victims will free up medical personnel. Overtriage must be avoided to ensure that limited hospital resources can focus on the most salvageable victims (generally people who are moderately wounded)..$^{30,31}$

\section{Subsequent EMS Actions}

Although search and rescue for entrapped victims may be ongoing after the first few hours, the Incident Commander (IC) will make decisions about staff and resource allocation, emphasizing those areas where EMS providers can use their skills to make the largest difference for the largest number of injured people. EMS may develop (or receive from public health sources) triage criteria to classify injured and fallout victims as expectant, and if this is the case, appropriate policies and procedures can ensure that patients receive what palliative care is available. (Further detail is provided by Murrain-Hill et $\mathrm{al}^{3}$ and Coleman et $\mathrm{al}^{32}$ ). The goal of helping the most people as possible includes both saving lives and providing comfort. The IC will request and incorporate outside agency resources (eg, ground, rotor-wing, fixed-wing) and anticipate the need for resources for future missions (eg, providing medical support on evacuation planes/buses/trains) to optimize the care of victims in the intermediate and delayed triage categories.

EMS personnel—indeed all personnel involved in responding to the incident-will have significant mental and behavioral health needs and issues, including the need to contact/locate family members, potential need for housing, and other assistance. Resources, rest, food, and resiliency information will be needed as soon as possible. Risk communication, consistent and timely information, and rumor control are as important for EMS personnel as they are for the public, because misinformation about contamination, exposure thresholds, and other issues will affect EMS staff and their ability to fulfill their job duties. (Mental health impact and management are discussed by Dodgen et al elsewhere in this issue of the journal. ${ }^{33}$ )

\section{Initial Health Care Facility Response Hospital Impact and General Response}

Based on estimates of casualties, ${ }^{1}$ overwhelming numbers of patients can be expected at the closest hospitals within the hour after the incident. The missions for these hospitals in the first hours are 3-fold:

1. Fully activate emergency response plans, including ferrying of needed resources to the facility (Hospital Incident Command System)..$^{34}$

2. Triage less severely injured patients to other facilities or waiting areas.

3. Provide stabilizing, not definitive care, to the largest number of patients possible given the resources and staff available.

With emergency plans activated, health care facilities will attempt to liaison with overall IC and with other area facilities and gain situational awareness, while providing either stabilizing or definitive care, depending on the demand and available
Health Care Facility Response Box 1: Key Principles for Initial Response

- The event will look very different to individual hospitals depending on their location in relation to the event and to the time after the event.

- The initial triage of patients should follow usual trauma priorities until symptoms, patient location relative to fallout, and laboratory testing allow for the assessment of severity of radiation injury.

- Radiation victim triage cannot be based on the presence of vomiting alone.

- The majority of early injuries presenting to the hospital will consist of penetrating and laceration injuries from glass and shrapnel.

- Containment of radioactive contamination on clothing is optimal (eg, provision of dry decontamination). Wet decontamination should not be a priority for facilities with large numbers of patients presenting for care. A cold outside temperature and a lack of exchange clothing may be a contraindication for wet decontamination. Many patients will have no radiation exposure.

- Radiation burns are not a dominant injury pattern after a ground-level detonation. They are a concern from an air burst detonation, and secondary fires may produce thermal burns.

- Hemorrhage control and damage control surgery for patients with isolated penetrating injuries are likely to be the best investment of resources to improve the most patient outcomes. At the hospitals located closest to the scene, intensive interventions such as surgery must be forgone to devote staff attention to external bleeding control and wound care.

- Alternate care locations for less-severe shrapnel/glass injuries (and later mild/moderate radiation illness) will be required. Facility and community plans should incorporate such centers. Some triage and alternate treatment sites may become interim assembly centers.

resources. Hospitals located further from the detonation may be asked to provide staff or resources to more overwhelmed hospitals or accept initially stabilized or patients with minor injuries in transfer from these facilities. Under these circumstances, personnel and supplies will need to be deployed and used carefully under an effective IC system so that functionality of these distal medical facilities is preserved.

\section{Radiologic Injury and Decontamination}

Assessment of degree of contamination and degree of radiologic injury is not an initial management priority for hospital personnel when life-and-limb-threatening trauma is present. Once the traumatic threats to life have been addressed, an assessment of the patient's scope of radiation injury should be undertaken to establish priority for cytokine treatment and further testing.

Hospitals located close to the blast that are overrun with victims should expect that some radioactive contamination of the facility will occur. Containment of radiologic contamination, including clothing control (including shoes) and self-decontamination (patients undressing and bagging their own clothing), should 


\section{Health Care Facility Response Box 2: Day 1}

Roy G. Biv was the lead emergency physician at Sacred Heart Hospital, a level 1 trauma center located $4 \mathrm{mi}$ from the downtown area. He was eating a doughnut when he heard a loud noise and rumble. EMS personnel standing on the ambulance drive were temporarily blinded by the flash of the detonation and unable to see. Based on the appearance of the cloud rising over downtown, Biv fully activated the hospital emergency operations plan. Callback pages were sent to critical clinical and administrative personnel. Supplies were brought to the ED per the disaster protocol. An ancillary triage area was designated in the hospital lobby. The "walking wounded" began to present within about 15 minutes and were directed to the lobby and an urgent care center down the street. Within $30 \mathrm{~min}-$ utes, critically injured victims were arriving at the hospital via private vehicle and later via EMS. All of the staff was occupied stopping bleeding from deep cuts from broken glass on the many victims. A decontamination area was established in the hospital parking lot, allowing noncritically injured victims to self-decontaminate by removing clothing and putting on hospital gowns. Patients who did not require immediate medical attention were excluded from entry into the ED and were referred to a nearby church, which is a preplanned assembly center. Operating rooms and critical care spaces were opened, but capacity was quickly overwhelmed. Patients were placed in hallways on all of the floors of the hospital, awaiting either surgery or imaging studies. Surgeons made decisions about priority for operative cases and performed many bailout procedures. The hospital command center requested area rotor-wing agencies to help ferry stabilized patients to other area hospitals with capacity for surgical critical care and to bring in additional surgical staff and equipment (eg, laparotomy trays, suture trays, dressings). Bus drivers were asked to move ambulatory patients to community hospitals and reception centers located several miles away from the hospital. As the event continued to unfold, information was faxed to the ED describing the pattern of heavy fallout based on field reports. Surgical staff determined that critically injured patients extricated from these areas presenting from the first hour after the event would be initially triaged as expectant.

be a priority at all times. These efforts alone can decrease a person's contamination by $\geq 90 \% .{ }^{6}$ Many trauma victims may have no radiation exposure, and even fallout-exposed victims may have no contamination on them. ${ }^{6,35}$ Doorway portal monitors or handheld monitors can help responders make rapid, qualitative assessments of contamination and direct decontamination/clothing control efforts. Radiologic contamination on feet is the most likely source of spread within the facility once clothing is controlled. As the resource situation allows, more formal patient radiation surveying and decontamination that is consistent with usual practices should be undertaken. ${ }^{35-37}$ Those that cannot perform selfdecontamination (eg, children, people with functional or physical impairments) should be assisted and escorted.

Protection of health care providers includes the usual barrier, mask, and glove precautions and appropriate types of dosimeter badges, which may include alarming electronic readout dosimeters for those with initial patient contact and routine radiation badges for others.

As resources allow, victims suspected of having been irradiated and hospitalized patients who cannot provide location/ exposure history that can be correlated with risk of radiation exposure should have an absolute lymphocyte count (ALC) performed $>12$ hours after the exposure. This screening will allow at least some categorization of exposure and prognosis and guide further decisions about care. If possible, a repeat ALC after 12 to 24 additional hours can more precisely define risk of complications and death. The Radiation Emergency Medical Management Web site ${ }^{36}$ provides dose-estimation calculators.

Patient prioritization by surgical, emergency, and critical care staff for interventions and/or transfer will be based on available resources. ${ }^{18,38}$ Movement of a limited number of temporized patients to other facilities via ground or air transportation within the first 1 to 2 days after detonation is resource intensive, but it may significantly relieve the pressure on intensive care and operating room resources. External transport agencies may be able to ferry supplies into the hospital and return patients to other regional facilities.

Using patient exposure history and ALC (if available), victims who are considered high priority for radiation injury treatment should receive myeloid cytokines (eg, granulocyte colonystimulating factor [G-CSF]) as soon as possible and receive their definitive surgeries within (optimally) a 48- to 72-hour window after injury, because surgeries delayed beyond that run a high risk for infection and healing failure as a result of the interval death of the tissue and hematopoietic cells necessary for surgical recovery and early healing. ${ }^{39,40}$ After life-and-limbsaving surgeries are complete, as many orthopedic and other surgical cases as possible should be completed in the first 48 to 72 hours after the detonation.

\section{Transportation and Tracking}

The amount of patient documentation performed according to the facility disaster plan will likely be much less than during routine operations. The key elements include a registration log listing patients seen and their diagnosis, disposition (including receiving facility if transferred), and contact information. Despite best efforts, the hospital may be unable to complete charting or track victims triaged away from the ED under these circumstances. Emergency planning may include details for requesting transportation resources from area air and ground EMS agencies, but also understanding the likely huge demand on these resources during these incidents.

\section{Unaccompanied Minors and Vulnerable Adults}

Children and other select patient groups whose parents or caregivers are incapacitated or unavailable may require lifesaving interventions that should be performed expeditiously. To avoid critical legal or bioethical complications that could paralyze the response system, relevant protocols should be developed as part of the planning process long before a disaster strikes. In addition, protocols for rapid reunification of children with parents or guardians should be available for activation after a catastrophic incident. Hospitals should also have plans in place for 
situations in which victim medical care is complete, but there is no caregiver or parent to accept the patient.

\section{Subsequent Hospital Response Issues}

Hospitals in the affected region should expect to receive large numbers of patients presenting with possible fallout radiation exposure in the days after detonation, including those with psychological effects that mimic radiation toxicity. There is a significant potential for these patient loads to dwarf the immediate postincident presentations, especially if timely sheltering instructions are not provided or followed. Assessment of these patients includes evaluation for complications related to vomiting and diarrhea. Those without severe symptoms can be discharged home. For patients with a high likelihood of acute radiation syndrome (ARS), hospitals would use existing supplies of myeloid cytokines for the "first dose" (eg, G-CSF) from available local stocks or caches and/or refer patients to receive this treatment where and when available from federal stockpiles. Triage approaches are described elsewhere in this special issue by Casagrande et $\mathrm{al}^{31}$ and Coleman and colleagues. ${ }^{32}$

Treatment with myeloid cytokines for patients who are expected to survive their radiation exposure and combined trauma may offer significant outcome benefit. ${ }^{2}$ Because of cost and shelf-life issues, however, few institutions, even bone marrow transplant centers, maintain more than usual use inventory or small caches of such medications. The federal Strategic National Stockpile ${ }^{41}$ program maintains inventories of cytokines for radiation disaster contingencies. These materials would be distributed to affected areas according to state and local planning for receipt of Strategic National Stockpile supplies. Health care facilities should work with public health authorities before an incident to ensure that this system is understood and practiced so that there is minimal delay in transporting the medications to the health care facilities. Even if mobilized immediately, there will be a likely delay of at least 24 hours until the medications begin to arrive at the facilities for use. Although these medications were stockpiled to address a major radiation event, demand may still exceed supply and allocation strategies may have to be implemented. ${ }^{32}$

The mental health issues noted in the EMS section are applicable. By 72 hours after the detonation, federal and other health care providers may be transitioning into the facility to replace or supplement usual hospital staff. Space considerations will continue to be an issue and will require good risk communication to direct less severely ill people to alternate care sites/assembly centers. The hospital incident management team will need to reevaluate their staffing and service priorities and resource needs each day and work with regional, state, and federal partners to ensure that the institution can continue to offer emergency and inpatient services. There may be a significant need for additional security, traffic control, and other law enforcement assistance; emergency management may have difficulty prioritizing health care facilities for scarce law enforcement resources in the immediate aftermath of an incident. Therefore, table-
Public Health Response Box 1: Key Principles for Public Health Agencies After a Nuclear Detonation

- Sheltering information should be provided to the public as rapidly as possible in conjunction with emergency management using emergency warning/notification/broadcast systems. Appropriate sheltering from fallout can dramatically reduce radiation injury casualties.

- The appropriate time to evacuate the fallout areas should be determined (in conjunction with emergency management and federal resources) and this decision communicated within hours of the initial sheltering order.

- Victims of fallout should be directed to screening sites and assessed for high-risk exposures based on subjective information (eg, location, shelter taken, current symptoms and signs). Those with higher predicted doses of radiation injury should ideally receive G-CSF within 1 day postexposure and be evacuated or directed to other population centers for care.

- Appropriate shelters should be opened to accommodate displaced people; there should be capacity and resources to provide for children and other vulnerable populations.

- Behavioral health and family reunification issues will be challenging in the immediate aftermath and require substantial planning.

- A mass fatality plan should be implemented and also the public informed that saving lives and providing care to survivors must take priority over body recovery when resources are scarce.

- Effective victim tracking early in the event will facilitate long-term monitoring.

top and other preincident exercises are important to establish the need and the mechanisms to obtain necessary resources.

A staff registry should track those staff involved in the response and their likely exposure levels. During this phase, more comprehensive assessment and some mitigation of the radiologic contamination of the facility can include temporary (eg, use of walkoff mats - plastic film or paper rolls used on construction sites - to prevent tracking through known contamination that cannot easily be cleaned up, replacement of hospital air filters that trap radioactive particulate debris) and definitive (eg, cleaning and/or removing contaminated tile and carpeting) procedures.

\section{Public Health}

\section{Initial Public Health Actions}

The public health challenges after a nuclear detonation will be myriad. A few key early actions can make a critical difference in the number of people injured by fallout and the number of lives that can be saved by evacuation to other regional or national population centers where sufficient medical resources are available. As an agency, public health will be uniquely taxed to keep up with not only the situational awareness but also integration of arriving resources (both requested and unrequested), informational demands, and response demands. These activities must be closely coordinated with those of the medical care sector, emergency management, emergency medical services, and public safety to ensure joint objectives and consistency of information to the responders, public, and me- 


\section{Public Health Response Box 2: Day 4}

Laurence Livermore is a 53-year-old man who was walking his dog when a massive explosion occurred behind him in the city's downtown area. He hurried home, but just before arriving there, he noticed particulate debris falling on him. He went inside his house, and shortly thereafter, the warning sirens began to sound. Although some television stations were not broadcasting, other stations carried warnings that people should move to the interior of buildings and stay inside. Laurence sheltered in place as instructed. About 4 hours later, he was instructed via television to remove and bag his clothing and shower with soap and water. The following morning, television and reverse 911 telephone calls instructed people living in specific ZIP codes to pack an overnight bag and report to 1 of several screening sites (opened at preidentified public health mass dispensing sites). Despite some nausea and vomiting, Laurence reported to the site, where he was asked several questions about his exposure, location during the fallout, and physical symptoms. He was sheltered overnight in a church. With his vomiting improved, he returned for reassessment to the screening site as directed. Because his ARS symptoms did not seem to indicate a poor prognosis, he received a wristband qualifying him for a daily dose of G-CSF adjacent to the screening area. He was counseled about his risks and it was strongly recommended to him that he be evacuated to another metropolitan area for observation and further care. He agreed, and 2 days later Laurence was bused to the airport was and then flown to another city. Hecompleted a demographic and health questionnaire en route. Upon arrival, the passengers were bused to an intake location, where their forms were reviewed by the local public health agency and they were referred either to hospitals or a local hotel for observation and continued treatment. Blood tests were taken at the hotel and daily symptom checks and medication administration clinics were made available in a hotel conference room.

dia. ${ }^{42,43}$ Public health will require significant support from partner agencies to accomplish these missions; these support roles and responsibilities should be defined preincident, as follows:

- Conduct preincident education instruction on the need to duck and cover if a massive flash of light is noted (rather than go to the window) and immediately take shelter in a similar manner for a tornado warning after any massive blast in the community until instructed further.

- Provide rapid information with respect to safety and timing of leaving initial shelters to escape the proximal blast zone and/or to receive appropriate medical attention.

- Identify and work with IC on situational awareness of damage and radiation levels and suggested actions for people in fallout areas.

- Coordinate modeling information supplied by multiple agencies (local, state, and federal) with environmental sampling/ reports of actual radiation levels to provide responders and emergency management with exposure information that is as accurate as possible. This will be difficult in such a dynamic situation. Preincident efforts to identify sources of information and ensure a means of reporting/coordination with public health are critical to success after a detonation.

- Rapidly open assembly and/or screening centers to evaluate and process displaced and evacuated people. Some centers may provide comprehensive services that include registration, question- naire completion (including physical location of victim at time of the blast, symptom course, medications, and medical history), first aid, radiation screening, dry decontamination, counseling, possible initial blood counts and initiation of myeloid cytokine treatment, and referral to appropriate next facility. ${ }^{44}$

- Open alternate care sites (that may be near assembly centers) in conjunction with EMS and hospitals to provide wound care services and hospital overflow, nonambulatory basic patient care. These sites can be located more remotely from the blast area. ${ }^{45-47}$

- Develop strategy for palliative care needs, which will be substantial, and will increase over time. If palliative care patients are well enough to travel (many in the latent phase of ARS), then strong consideration for evacuation should be given.

- Support for mass care (sheltering) for people who evacuated the fallout areas and cannot identify other housing. Pet care and sheltering also must be addressed. ${ }^{48}$ All centers and shelters must have adequate provisions to care for children (accompanied or not accompanied by parents or guardians) and others with special needs.

- Provide risk communication, including when to (and when not to) seek medical care ${ }^{49}$ and frequent and timely incident updates. Address rumors and misinformation.

\section{Subsequent Public Health Activities}

- After the delineation of fallout zones and exposure rates, such information must be disseminated widely so victims seeking treatment in other regions can be assessed and treated appropriately.

- Victims of infrastructure loss such as those who are dependent on medical technologies (eg, home ventilators, oxygen, dialysis) will require support to ensure that treatments are continued during evacuation and sheltering.

- Registration and tracking of exposed and evacuated people will be a daunting process. If a paper-based form is used initially, then the transfer of this information to electronic media and creation of a master file will facilitate victim tracking during and after the incident; family reunification; and identification of dead or missing people. Development of integrated systems that are capable of tracking across state lines and systems remains a high priority. ${ }^{50}$ These systems and protocols will be necessary to ensure rapid reunification of families that have been displaced or separated.

- Evacuation of salvageable fallout casualties in the latent phase of their illness to areas of the nation with appropriate medical capacity will likely begin within the first week after detonation. Thus, movement of more severely injured, nonambulatory patients will be a priority in the first few days after the incident, and movement of ambulatory (and relatively well, because they are in the latent phase of ARS) fallout casualties a priority in days 3 through 10 (although this movement can occur earlier if resources allow).

- As the fallout casualties are evacuated and the medical system stabilizes from both transfers and an influx of resources, attention can be focused on the myriad shelter health, environmental health, population monitoring, behavioral health, and atrisk population issues. Although critical to the overall success of a public health response, in-depth discussion of these issues is beyond the scope of this article. 


\section{Medical System Response}

Hospitals throughout the region will implement surge capacity plans ${ }^{51,52}$ and may have to adjust their standard of care to a situational standard of crisis medical care. ${ }^{1,13,53-55}$ Triage decisions will be necessary to optimize saving lives and providing palliative care to the extent possible (discussed further elsewhere in this special issue by $\mathrm{DiCarlo}$ et $\mathrm{al},{ }^{2}$ Caro et al, ${ }^{56}$ Casagrande et $\mathrm{al},{ }^{31}$ and Coleman et $\mathrm{al}^{32}$ ).

The heterogeneous situation across local and regional health care systems has been described by Knebel et $\mathrm{al}^{1}$ and DiCarlo et al. ${ }^{2}$ The importance of fairness to victims, albeit in a crisis standards of care mode, is enhanced by regional preparation to harmonize crisis standards of care and triage policy through integrated information and resource sharing among health care institutions. Communications may be severely compromised both within and between facilities and disciplines after a nuclear incident, requiring redundant communications planning. ${ }^{57}$

\section{Regional Coordination of Medical Resources}

Establishment of Health and Medical Coordination Centers (HMCCs) will facilitate the ability of multiple health care facilities in the area to quickly gather incident information and logistical needs, and to act in coordination with public health, EMS, and emergency management. Highly effective implementation of HMCC shas occurred in major hurricanes that required mass evacuations of civilians and hospitalized patients. ${ }^{17,58}$ The formation of these centers has been described in several articles and texts. ${ }^{53,59}$ The formation of hospital coalitions, which define the ability of health care facilities to provide mutual assistance, exchange information, distribute resources, and function as an interface/ clearinghouse for the regional hospitals, is now a requirement of the DHHS hospital preparedness grant program. ${ }^{5,60,61}$

Private and government- (eg, Department of Veterans Affairs) owned health care systems often have disaster plans that obtain support for their system hospitals from other facilities outside the affected area. As demand exceeds resources, a tiered system of stepwise mobilization of resources will be involved so that the resourcedemand mismatch is corrected as quickly as possible, usually with a combination of resource supply and patient evacuation. This system is well described by Barbera and Macintyre in the Medical Surge Capacity and Capability Handbook ${ }^{62}$ and expanded upon in other articles. ${ }^{53,63-67}$

Hospital coalitions must identify an interface and process by which health care, EMS, public health, and emergency management jointly ensure that federal Emergency Support Function $\# 8^{68}$ functions are accounted for. These operations or coordination centers may cross jurisdictional boundaries, or in a single jurisdiction may be part of the emergency operations center. An effective interface will act as a clearinghouse for information, resource requests, transfer requests, and transportation assets matching so that there is coordination across the disciplines, as competing priorities for buildings, transportation, medications, staff, law enforcement support, and other assets is ensured (eg, a convention center may be desired by
Medical System Response Box 1: Key Principles for Medical System Response to a Nuclear Detonation

- Situational awareness is likely to be limited in the first few days.

- Preexisting regional coalitions and management/coordination constructs should be used to optimize use of available health care resources and to obtain more rapid situational awareness. Coalitions must have redundant plans for command and control in case the usual coordination points or personnel are unavailable.

- Systems must be in place to assess, coordinate, and deploy new assets as they arrive on scene (federal and state governments, surrounding regions, private organizations, and volunteers) in an organized and effective manner.

- A common operating picture, objectives, and policies should be developed with emergency management, public health, EMS, and hospitals to optimize use of their limited resources and manage arriving external support.

- Public communication, both basic information and risk communication, should be used to reduce unnecessary demands on the medical system. This should be coordinated with federal government messaging.

- Medical coordination should diffuse the medical impact by evacuating patients to other areas of the region and nation that have adequate capacity. Initial focus on rapid transfer of nonambulatory trauma casualties may require modification based on resource availability.

- Specific attention must be paid to the availability of pediatric resources in the region and beyond to optimize the survival of children who have been injured, burned, or exposed to radiation.

- Fallout casualties may need early intervention to mitigate ARS, although they may not appear to be seriously ill.

- Medical support at assembly centers and alternate care sites will be needed, and the health care system will be called on to assist in/ coordinate these efforts.

emergency management for shelter, by public health as a screening site/assembly center, and by hospitals as an alternate care site). These constructs are best practiced preincident, using multiagency coordination system principles. ${ }^{69}$ Notably, most of these constructs are referred to as coordination rather than command centers because they may cross jurisdictions and include private EMS and hospital partners that are voluntary participants in the process and not commanded by an agency or jurisdiction.

Coordination between the HMCC and local, state, and regional emergency operations centers will facilitate requesting and receiving assistance; coordinating available beds, resources, and transportation; and reducing confusion. Incident management teams from outside the affected area may be deployed and used to great utility to coordinate the process of incident management. ${ }^{70}$ Technologies such as Web-based information sharing systems and conference calls also can be invaluable tools.

In this scarce-resources setting the HMCC can develop utilization policy in conjunction with state and technical experts (eg, issuing real-time guidance for use of myeloid cytokines). The HMCC can also work closely with public health authorities to ensure consistency of public messages regarding these allocation decisions. 


\section{Medical System Response Box 2: Day 5}

Millie Gray, the coordinator leading the Emergency Support Function \#8 "Public Health and Medical Services" regional response, has just briefed the county emergency manager, key local elected officials, state health department liaison, and public health director on the situation 5 days after the detonation. One of the 30 hospitals was in the severe damage zone and was destroyed as a result of the blast. Most of the staff, visitors, and patients remain unaccounted for. Two additional hospitals had substantial window damage and undertook a phased evacuation of their facilities after providing initial care to self-referred patients. Patients who could be easily evacuated to on-campus collection sites were moved. Seriously ill adults and the children awaiting skilled medical evacuation were cared for in units with makeshift window coverings. EMS units were transporting acutely injured victims to functioning hospitals, so many less seriously injured were evacuated by buses and other vehicles to regional hospitals within the same network. Critically ill patients required substantially more transport capability. Nongovernment rotor-wing assets were used to move unstable patients, including those from a large neonatal and pediatric intensive care unit. The evacuation of these patients took nearly 2 days. As ambulances from distant regions arrived, provided by the federal ambulance contract, they were used to transport seriously ill adults. The evacuation of the 2 hospitals was completed on day 4 .

Many other hospitals, especially the 6 closest to the blast site (not including the 3 that were damaged) have been inundated with severe traumatic injuries. Centers that do not usually receive trauma patients had to manage many such patients, who arrived by all imaginable modes of transportation. These patients could not be redistributed easily to other hospitals. There had been confusion about timing surgical procedures for patients with suspected radiation exposure. Volunteers from a local college were used to assist with epidemiologic data collection to estimate the radiation exposure for each trauma victim until a biodosimetry protocol was implemented. Cytokine assets began arriving from the Strategic National Stockpile on day 1 , and although there was confusion initially about who should receive them and how they should be distributed, public health, hospitals, and emergency management were able to figure out a system and provide more consistent guidance by day 3 .

Many staff were killed, injured, or mourning lost friends and family; others could not come to work because of family obligations. Despite heroic efforts, caregiving in the first days was chaotic and limited by the availability of staff and medical resources. By day 5 , hospital functions were becoming more stable, with federalized medical personnel providing relief.

The regional health and medical coordination center (HMCC) was established on day 1 , and situational awareness of health system function was extremely limited at that time. Because local hospitals were already inundated with seriously ill and injured people, alternate sites were needed to screen patients for significant radiation exposure and to provide minor care. Furthermore, a number of people with complex chronic medical conditions who were living in the community were arriving at hospitals seeking oxygen, dialysis, and other assistance. Alternate care sites were opened in conjunction with public health authorities at preselected sites that did not conflict with screening sites. The alternate care facilities were located in the same buildings as screening, to optimize the use of personnel for administrative, logistics, and security functions. The coordination center developed patient lists for the National Disaster Medical System (NDMS) and coordinated with EMS transport to the airport. By day 5, federal staff were providing care at the alternate care facilities, which quickly filled with people with complex care needs who had no caregiver or safe sheltering options. Additional federal medical stations were in the process of being set up to provide better and safer special needs shelters. Six of these 250 bed units were expected to be operational in preidentified facilities within the next 48 hours. A federal incident management team had arrived to assist in health and medical planning and logistics at the HMCC.

Surrounding states and regions also will be affected and may be forced to activate their own coordination systems. Indeed, receiving communities may have to implement selective resource triage (eg, national rationing of myeloid cytokines may occur, with guidelines circulated by DHHS and other agencies) to ensure consistency and fairness. Coordinating the surveillance and medical management of evacuees and communicating with DHHS about their status and progress will require substantial personnel and material resources.

Qualified staff may be in severe shortage in the early aftermath of a nuclear detonation incident due to issues relative to the ability to access the health care facility, impact of the incident on family, and the very real possibility that a segment of health care workers will decide not to report for work because of concerns about the risk of suffering personal health effects. ${ }^{71,72}$ Unfortunately, willingness to report to work after a radiation incident is particularly low: Only $49 \%$ of nurses surveyed by Lanzilotti et al would report for duty ${ }^{73}$ Interestingly, personnel with the least training or knowledge for these special response situations also had the least desire for additional training. This has significant implications for our ability to increase willingness to respond by building expertise through education. ${ }^{74}$ Preincident education with an emphasis on risk perception vs actual risk is likely still the best method to improve workforce response. Just-in-time educational efforts also will be important to combat rumors and address conflicting information, thus allowing health care personnel to make informed decisions about their personal risks.

Finally, because of the specialized needs of severely injured or radiation-exposed children, regional disaster medical response planners and relevant national organizations (eg, the National Association of Children's Hospitals and Related Institutions) should consider where and how children will be transported to appropriate facilities under the circumstances of a large-scale disaster with many pediatric victims.

\section{Evacuee Medical Care and Fallout-Related Radiation IIIness}

The medical management of ARS is discussed by DiCarlo and coauthors. ${ }^{2}$ The Radiation Injury Treatment Network $(\text { RITN })^{75}$ serves as a technical and operational resource after radiation injury incidents. Although it is likely that 
preference would be given to utilizing member hospitals of the $\mathrm{NDMS}^{76}$ and RITN facilities, the magnitude of a nuclear detonation incident is such that all of the facilities in the surrounding region and most tertiary care facilities in the nation may receive patients, either by formal referral or self-referral. Thus, a community plan to receive and treat such patients should be accounted for at all major health care facilities. The RITN network health care facility guidance and communication and coordination plan may be a resource to other facilities planning for these victims. ${ }^{3,75}$ NDMS, RITN, and nonparticipating facilities capable of treating pediatric ARS must be preidentified.

Most victims with the hematologic subsyndrome of ARS will be ambulatory and feel reasonably well for the 1- to 2-week latent period; therefore routine forms of transportation can be used to reach referral sites throughout the nation. ${ }^{77}$ Most will need medical monitoring but not hospitalization.

Although the number of people exposed to radiation may be large, a decreasing number will require cytokines, outpatient care, inpatient care, and stem cell transplant (Figure 2). Despite the proportional decrease, the numbers of people requiring treatment with cytokines, platelets, and other support may greatly exceed national availability, requiring state, federal, and discipline-specific (eg, American Association of Blood Banks, American Red Cross) guidance on conservation and allocation of such resources.

Jurisdictions should plan in coordination with public health, emergency management, and the medical community so that there is a shared understanding of the responsibilities for these evacuees. Because most of the patients will need ongoing monitoring but not hospitalization, plans for accommodations (hotels, special needs shelters), outpatient medical care and monitoring, referral for inpatient treatment, and patient tracking and family information and reunification are core elements of such planning. Coordination mechanisms among health care facilities and the local jurisdictions, states, and federal agencies will be required to fairly address multiple and competing resource needs and shortfalls, and address issues in what will certainly be a dynamic response environment in which many policies and procedures will be developed de novo.

\section{Recovery}

The Scarce Resources for a Nuclear Detonation Project did not formally address issues of recovery, but some key objectives are included in the present article because recovery planning must begin during the response phase.

A nuclear detonation will have unpredictable military and economic consequences that create hardships for the entire nation. A new pool of citizens will be created that will require lifelong monitoring and specialized care. Many will experience at least transient behavioral health effects that may compromise resilience and increase the support required. (Psychological issues are discussed further by Dod-
Evacuee Medical Care and Fallout-Related Radiation Illness Box 1: Key Principles in Care of Fallout-Related Radiation Illness

- Patient tracking and family reunification will be key objectives.

- Major population centers, cancer center/bone marrow transplant units and cancer centers (Radiation Injury Treatment Network [RITN]) may receive large numbers of falloutinjured patients.

- Early assessment of ALC or other biodosimetry assays can help predict prognosis and need for treatment.

- Prioritization for cytokine (eg, G-CSF) treatment will be necessary. ${ }^{2}$

- The majority of evacuated patients will not require hospitalization.

- Receiving communities will need an integrated approach to the receipt, in-processing, surveillance, housing, and medical care of these specialized patients.

- Protocols for the diagnosis, transport, and treatment of children with ARS should be planned well before an actual nuclear detonation.

Recovery Box 1: Key Principles During the Recovery Phase

- Medical monitoring and care will be ongoing and, in some cases, complex.

- Social and behavioral health issues will become dominant after the initial acute medical care period and will require multidisciplinary approaches.

- Family reunification systems will need to be activated and aggressively implemented.

- Continuity of access to health care and essential social systems will be essential to meet victim needs.

- A rapid return to a state of normalcy with respect to appropriate permanent housing, schooling, community services, and other essential systems will be essential to reduce the long-term psychological impact on children and families.

- A significant portion of the evacuees will be permanently displaced, posing significant problems with the continuity of their complex medical and social care.

- Ongoing risk communication is critical to provide accurate information, dispel rumors, and provide assessment of delayed risks from radiation.

- Long-term monitoring should be done for those deemed to be at risk for late radiation-induced damage or cancer. Who requires monitoring will require expert input from epidemiologists.

- Long-term follow-up and registries will be needed for other physical injuries and psychiatric support.

gen et al. ${ }^{33}$ ) Significant public and social program support for displaced and injured people is the joint responsibility of local, state, regional, and tribal governments along with the federal government.

After the initial response phase, it is likely that victims and providers will experience a fatigue and disillusionment phase during which victims will feel abandoned and providers bur- 


\section{Medical System Response Box 2: Day 14}

Marie Curie is the lead nurse on the hematopoietic stem cell transplant unit at an academic medical center in the San Francisco, CA, area. She had not been able to contact her husband's cousin, who lived about $10 \mathrm{mi}$ from ground zero, and was sleepless and frequently tearful.

Two days after the detonation, her hospital was asked to prepare for 100 to 200 victims during the next 7 to 10 days. The hospital's command system was immediately activated. Adequate space was being planned to accommodate the victims, including canceling elective cases and identifying patients for transfer to other facilities or discharge during the next several days. Specific supplies including G-CSF, antibiotics, and burn wound dressings had been stockpiled from local vendors and pharmacies. Oncology nurses immediately organized training for practitioners who did not have prior experience with these complex patients.

Victims began arriving 4 days after the detonation. Commercial airliners provided ambulatory patient transport of fallout casualties whose exposure and symptoms were consistent with moderate (2-6 Gy) exposure and who were now in the latent phase of their illness. Some had received G-CSF and lymphocyte counts, whereas others had not. More than 100 patients arrived on each plane, accompanied by a few medical practitioners. The initial patients appeared to be relatively well, although they were fatigued and some had vomiting and diarrhea on the flight.

By day 10 , more severely injured radiation victims, including patients who had undergone surgery at other centers, were arriving via military aircraft. During the next few weeks, many of the initial patients became severely neutropenic and required extensive supportive care, including broadspectrum antibiotics, transfusions, and intravenous fluids. During this time, Marie attended a daily meeting to review issues related to scarce resources, brainstorm for solutions, and develop or modify plans for resource allocation.

One of Marie's patients, Laurence Livermore, was transferred to San Francisco via commercial airliner 4 days after the detonation. He arrived with few records, but according to him, he received G-CSF on 2 of the first 4 days. His vomiting and cutaneous erythema improved after 2 days, but he developed watery, profuse diarrhea. On arrival, his absolute neutrophil count was 0 and it remained low despite daily G-CSF. He was hospitalized for antibiotics and supportive care. His sister, who lives in Iowa, was contacted and her blood was drawn for human leukocyte antigen typing. Based on buccal swab DNA, unrelated donors through the National Marrow Donor Program were being sought. Fortunately, Mr Livermore's most recent absolute neutrophil count had increased to 0.2 .

\section{FIGURE 2}

\section{Distribution of care requirements for fallout-exposed patients evacuated to other areas}

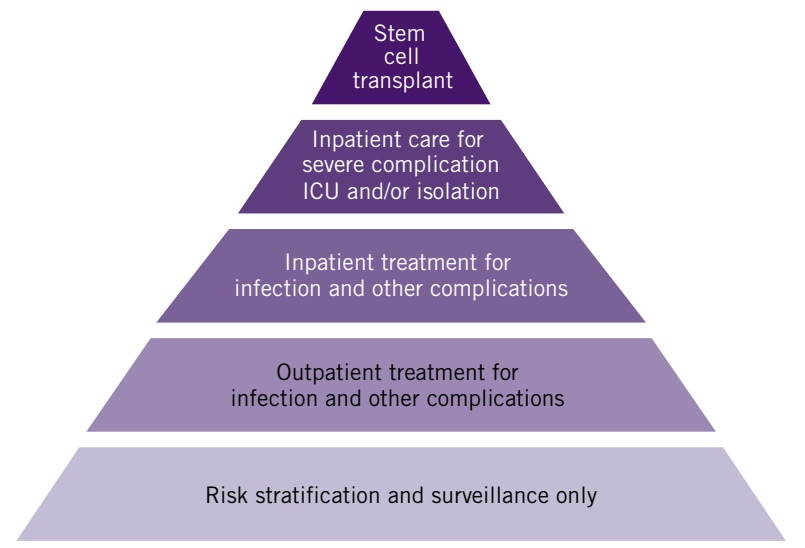

dened, and psychological manifestations of the trauma continue to evolve. ${ }^{78-80}$ During this phase, long-term management of burn, trauma, and radiation-related injuries will continue, with ongoing stress on hematology, burn, and rehabilitation centers. Monitoring and treatment for delayed effects of acute radiation exposure ${ }^{40,81}$ will be initiated. Problems identifying and tracking victims will likely lead to continuity of surveillance and care issues as victims move closer to family, friends, or jobs.

Victims are likely to receive inaccurate information regarding treatments, alternative treatments, and risk from a variety of sources. Well-meaning health professionals may create confu- 
sion if they do not have adequate information about the risk of cancer, genetic, and noncancer effects postexposure. Thus, a priority in the recovery phase is on the development of and circulation to victims and providers of accurate information about treatment, long-term risk, and outcomes of their injury or injuries. Rumor control and specific official information addressing inappropriate or unhelpful treatments is mandatory to prevent victim and provider confusion.

Many victims will have extraordinary social and behavioral health support requirements. Children will be particularly vulnerable to severe and long-term mental health and behavioral consequences. In addition, their families, providers, and the community at large will experience long-term psychological effects. $\mathrm{Pa}$ tients with preexisting psychiatric illness will be extremely destabilized by the incident and will have increased care requirements. Displacement and behavioral health issues are not rapidly resolved. Six years after Hurricane Katrina, two-thirds of displaced children exhibit emotional or behavioral problems and half remain in temporary housing. ${ }^{82}$ The National Child Traumatic Stress Network ${ }^{83}$ can coordinate best-practices assistance in the recovery phase to support unique pediatric behavioral health needs after a disaster. A new office of the Assistant Secretary for Preparedness and Response, the Office for At-Risk Individuals, Behavioral Health, and Human Services Coordination, has been

\section{Recovery Box 2: Day 122}

Clara Barton is a social worker at the Iowa City Veterans Affairs Medical Center and works at the clinic designated for long-term follow-up of people affected by the nuclear detonation. Today is the 4-month anniversary of the detonation, which has been particularly emotional for everyone. The clinic's nuclear response team is a multispecialty group that includes medical practitioners, mental health professionals, physical and occupational therapists, and data collection managers. The social work-related needs for patients have been extensive. Many patients are not from Iowa City and require help with temporary housing, financial support, reconnecting with loved ones, job placement, and transportation. A federal government tracking system studies the outcomes and provides support for victims, but it involves a significant amount of paperwork.

One of Clara's patients, Laurence Livermore, moved from San Francisco, where he was hospitalized for 6 weeks, to Iowa City so that he could be closer to his sister. He lives in survivor housing in a university dormitory. Mr Livermore comes to the clinic weekly and is seen by a nurse practitioner, psychologist, and social worker. His CD4 count remains under 200, but his other blood counts and chemistries have normalized. He says he continues to feel "sad and anxious" and voices feelings of guilt about being prioritized for treatment while others were "left to die." He has difficulty sleeping and concentrating and does not feel capable of going back to work. He continues to be guilt ridden about leaving his dog at the assembly center, and has not been able to find him despite many attempts.

\section{TABLE}

\section{Example of Response During the First Few Days \\ Days \\ 1 \\ Increased search and rescue of wounded Large volume of radiation illness patients (vomiting not reliable symptom) \\ Coordinate with outside resources \\ Assist with/coordinate trauma transfers (or delegate to EM) \\ $3-4$ \\ Public Health \\ Sheltering orders, evacuation orders, working with federal assets (FRMAC, A-Team) \\ Open assembly centers for minor care/shelter (with EM) \\ Communicate to at-risk fallout population Open screening centers \\ Receive SNS assets and distribute \\ Prepare to evacuate salvageable fallout casualties days 3-7 \\ Continue/refine screening and begin G-CSF administration as available \\ Begin to evacuate fallout casualties (as they enter latent period) to RITN or major population centers \\ Palliative care centers/options required \\ Health Care Facility \\ Activate emergency operations center/incident command system \\ Assess facility for damage/maintain operations \\ Triage, treatment of victims of trauma/combined injury \\ Begin G-CSF treatment as appropriate, if available \\ Reassess and reprioritize patients based on evolving evidence of combined injury, obtain lymphocyte counts \\ Determine patients for evacuation/forward movement via NDMS or local assets (limited evacuation may occur during this time) \\ Patients presenting with acute radiation illness from fallout and continued minor trauma from initial blast require treatment/referral \\ Begin patient evacuation to centers with capacity \\ Prepare to and begin integrating external staff and resources as applicable/needed \\ Complete surgeries if possible on combined injury patients \\ Continued high volumes of patients with radiation injury \\ EM \\ Issue warnings and information Disaster declarations initiated Shelters opened \\ Joint public information center Coordination with state/federal entities Process resource requests and resulting logistics \\ Refine event modeling with federal assistance \\ Mass fatality management: for immediate and expected radiation-related deaths \\ Integrate arriving resources \\ Determine plans for ongoing sheltering and evacuation of injured and \\ noninjured \\ Continue to process resource requests}

A-Team = Federal Radiologic Advisory Team for Environment, Food, and Health; EM=emergency management; EMS=emergency medical services; FRMAC=Federal Radiologica Monitoring and Assessment Center; G-CSF=granulocyte colony-stimulating factor; NDMS = National Disaster Management System; RITN=Radiation Injury Treatment Network; SNS $=$ Strategic National Stockpile. 
formed to attempt to bring consistency and integration to planning and response for these populations. ${ }^{83}$ The degree of disruption, displacement, and damage posed by a nuclear detonation radically complicates efforts to return the victims to as much normalcy as possible, yet this must continue to be the overarching goal of recovery.

Within the first few years after the incident, myelodysplastic syndromes may develop, with radiation-induced solid tumors occurring many years or decades later, in a subset of exposed people. In fact, any adverse medical event in the population exposed to $>1$ or 2 Gy will become an issue.

The recovery phase of a nuclear incident is exceptionally prolonged in relation to other catastrophic incidents that do not require lifetime surveillance and ongoing care. No other disaster will affect the lives of the victims, their families, and providers as profoundly.

\section{Integration of Actions Across Health Care Sectors}

The Table is an example of the key components of the response and how they fit together.

\section{CONCLUSIONS}

A nuclear detonation presents challenges of unprecedented scale. As massive as it is, an effective medical response can save lives and provide comfort on an unprecedented scale. Preplanning enables proper decision making, effective communication, maintenance of a command/coordination structure, optimal resource management despite initial scarcity, and thoughtful application of medical triage guidance.

This article has outlined key considerations for the overall health care system that support the decision points detailed in the state and local planners playbook. ${ }^{3}$ The authors believe that this article will facilitate and stimulate additional planning and education that would bring us as close as possible to preparedness for what once was an impossible incident, but one for which an effective response, including community and national medical system resilience, would provide benefit to millions.

Author Affiliations: Dr Hick is with the Hennepin County Medical Center, University of Minnesota; Dr Weinstock is with the Dana-Farber Cancer Institute, Harvard Medical School; Drs Coleman, Bader, and Knebel and Ms Murrain-Hill are with the Office of the Assistant Secretary for Preparedness and Response, Department of Health and Human Services; Dr Hanfling is with the Department of Emergency Medicine, The George Washington University; Dr Cantrill is with the Department of Emergency Medicine, Denver Health Medical Center; and Dr Redlener is with the Mailman School of Public Health, Columbia University.

Correspondence: Address correspondence and reprint requests to Dr John L. Hick, Hennepin County Medical Center, 701 Park Ave S, Minneapolis, MN 55415 (e-mail: john.hick@hcmed.org).

Received for publication September 19, 2010; accepted January 28, 2011. This article was corrected on March 25, 2011.

The US Department of Health and Human Services (DHHS) provided funding to support this publication and convene the authors. The contents of the articles represent the personal views of the individual authors and do not necessarily express the opinion or policy of DHHS or its components. No statement in the articles should be construed as an official position of DHHS or its components.

Author Disclosures: The authors report no conflicts of interest.

Acknowledgment: The authors acknowledge the contribution of Alicia Livinski, biomedical librarian, National Institutes of Health Library, for assistance with the preparation of this article.

\section{REFERENCES}

1. Knebel AR, Coleman CN, Cliffer KD, et al. Allocation of scarce resources after a nuclear detonation: setting the context. Disaster Med Public Health Prep. 2011;5(Suppl 1):S20-S31.

2. DiCarlo AL, Maher C, Hick JL, et al. Radiation injury after a nuclear detonation: medical consequences and the need for scarce resources allocation. Disaster Med Public Health Prep. 2011;5(Suppl 1):S32-S44.

3. Murrain-Hill P, Coleman CN, Hick JL, et al. Medical response to a nuclear detonation: creating a playbook for state and local planners and responders. Disaster Med Public Health Prep. 2011;5(Suppl 1):S89-S97.

4. Franco C, Toner E, Waldhorn R, Maldin B, O'Toole T, Inglesby TV. Systemic collapse: Medical care in the aftermath of Hurricane Katrina. Biosecur Bioterror. 2006;4(2):135-146.

5. Maldin B, Lam C, Franco C, et al. Regional approaches to hospital preparedness. Biosecur Bioterror. 2007;5(1):43-53.

6. Planning Guidance for Response to a Nuclear Detonation. 2nd ed. Washington, DC: Homeland Security Council, Interagency Policy Coordination Subcommittee for Preparedness and Response to Radiological and Nuclear Threats; May 6, 2010. http://hps.org/hsc/documents/Planning _Guidance_for_Response_to_a_Nuclear_Detonation-2nd_Edition_FINAL pdf. Accessed February 7, 2011.

7. Coleman CN, Knebel AR, Hick JL, et al. Scarce resources for nuclear detonation: project overview and challenges. Disaster Med Public Health Prep. 2011;5(Suppl 1):S13-S19.

8. Iserson KV, Moskop JC. Triage in medicine, part I: Concept, history, and types. Ann Emerg Med. 2007;49(3):275-281.

9. Dacey MJ. Tragedy and response- the Rhode Island nightclub fire. N Engl J Med. 2003;349(21):1990-1992.

10. Hirshberg A, Holcomb JB, Mattox KL. Hospital trauma care in multiplecasualty incidents: a critical view. Ann Emerg Med. 2001;37(6):647-652.

11. Klein KR, Pepe PE, Burkle FM Jr, Nagel NE, Swienton RE. Evolving need for alternative triage management in public health emergencies: a Hurricane Katrina case study. Disaster Med Public Health Prep. 2008;2 (Suppl 1):S40-S44.

12. Kirschenbaum L, Keene A, O'Neill P, Westfal R, Astiz ME. The experience at St. Vincent's Hospital, Manhattan, on September 11, 2001: preparedness, response, and lessons learned. Crit Care Med. 2005;33(1) (Suppl):S48-S52.

13. Institute of Medicine. Guidance for Establishing Crisis Standards of Care for Use in Disaster Situations: A Letter Report. Washington, DC: National Academies Press; 2009.

14. Koenig KL, Goans RE, Hatchett RJ, et al. Medical treatment of radiological casualties: current concepts. Ann Emerg Med. 2005;45(6):643-652.

15. Burstein JL. The myths of disaster education. Ann Emerg Med. 2006;47(1): 50-52.

16. Peleg K, Aharonson-Daniel L, Stein M, et al; Israeli Trauma Group (ITG). Gunshot and explosion injuries: characteristics, outcomes, and implications for care of terror-related injuries in Israel. Ann Surg. 2004;239(3): 311-318.

17. Hamilton DR, Gavagan T, Smart K, et al. Houston's medical disaster response to Hurricane Katrina: part 2: transitioning from emergency evacuee care to community health care. Ann Emerg Med. 2009;53(4):515-527.

18. Einav S, Aharonson-Daniel L, Weissman C, Freund HR, Peleg K; Israel Trauma Group. In-hospital resource utilization during multiple casualty incidents. Ann Surg. 2006;243(4):533-540.

19. Sasser SM, Hunt RC, Sullivent EE, et al; National Expert Panel on Field 
Triage, Centers for Disease Control and Prevention (CDC). Guidelines for field triage of injured patients. Recommendations of the National Expert Panel on Field Triage. MMWR Recomm Rep. 2009;58(RR-1):135.

20. Military Health System, US Department of Defense. Tactical combat casualty care curriculum. http://www.health.mil/Education_And_Training /TCCC.aspx. Published March 11, 2010. Accessed August 17, 2010.

21. Borden Institute, Walter Reed Army Medical Center. Triage. In: Emergency War Surgery. 3rd ed. Washington, DC: US Department of Defense; 2004:3.1-3.17. http://www.bordeninstitute.army.mil/other_pub/ews /Chp3Triage.pdf. Accessed February 28, 2011.

22. Federal Emergency Management Agency, Department of Homeland Security. National Incident Management System. http://www.fema.gov /emergency/nims/index.shtm. Accessed August 17, 2010.

23. Office of Radiation Programs, Environmental Protection Agency. Manual of protective action guides and protective actions for nuclear incidents. http://www.epa.gov/rpdweb00/docs/er/400-r-92-001.pdf. Published 1992. Accessed August 17, 2010.

24. González AJ. Lauriston S. Taylor Lecture: Radiation protection in the aftermath of a terrorist attack involving exposure to ionizing radiation. Health Phys. 2005;89(5):418-446.

25. Hogan DE, Waeckerle JF, Dire DJ, Lillibridge SR. Emergency department impact of the Oklahoma City terrorist bombing. Ann Emerg Med. 1999;34(2):160-167.

26. Benson M, Koenig KL, Schultz CH. Disaster triage: START, then SAVE-a new method of dynamic triage for victims of a catastrophic earthquake. Prehosp Disaster Med. 1996;11(2):117-124.

27. Lerner EB, Schwartz RB, Coule PL, et al. Mass casualty triage: an evaluation of the data and development of a proposed national guideline. Disaster Med Public Health Prep. 2008;2(Suppl 1):S25-S34.

28. Sasser SM, Hunt RC, Sullivent EE, et al. Guidelines for field triage of injured patients. Recommendations of the National Expert Panel on Field Triage. JEMS. 2009;34(Suppl 1):35-39.

29. Demidenko E, Williams BB, Swartz HM. Radiation dose prediction using data on time to emesis in the case of nuclear terrorism. Radiat Res. 2009; 171(3):310-319.

30. Frykberg ER, Tepas JJ III. Terrorist bombings. Lessons learned from Belfast to Beirut. Ann Surg. 1988;208(5):569-576.

31. Casagrande R, Wills N, Kramer E, et al. Using the model of resource and time-based triage (MORTT) to guide scarce resource allocation in the aftermath of a nuclear detonation. Disaster Med Public Health Prep. 2011; 5(Suppl 1):S98-S110.

32. Coleman CN, Weinstock DM, Casagrande R, et al. Triage and treatment tools for use in a scarce resources-crisis standards of care setting after a nuclear detonation. Disaster Med Public Health Prep. 2011;5(Suppl 1):S111-S121.

33. Dodgen D, Norwood AE, Becker SM, et al. Social, psychological and behavioral responses to a nuclear detonation in a US city: implications for health care planning and delivery. Disaster Med Public Health Prep. 2011; 5(Suppl 1):S54-S64.

34. Hospital Incident Command System Guidebook http://www.emsa.ca.gov /HICS/files/Guidebook_Glossary.pdf. Published August 2006. Accessed May $1,2010$.

35. Runge JW, Buddemeier BR. Explosions and radioactive material: a primer for responders. Prehosp Emerg Care. 2009;13(4):407-419.

36. National Library of Medicine, National Institutes of Health. Radiation Emergency Medical Management. http://www.remm.nlm.gov. Accessed May $6,2010$.

37. Radiation Emergency Assistance Center/Training Site (REAC/TS), Oak Ridge Institute for Science and Education. The Medical Aspects of Radiation Incidents. http://orise.orau.gov/files/reacts/medical-aspects -of-radiation-incidents.pdf. Published 2010. Accessed February 11, 2011.

38. Frykberg ER. Medical management of disasters and mass casualties from terrorist bombings: how can we cope? J Trauma. 2002;53(2):201-212.

39. Rojas-Palma C, Liland A, Jerstad A, et al. TMT Handbook. Triage, Monitoring and Treatment of People Exposed to Ionising Radiation Following a Malevolent Act. http://www.nrpa.no/dav/de688664a2.pdf. Published 2009. Accessed February 11, 2011.
40. International Atomic Energy Agency. Generic Procedures for Medical Response During a Nuclear or Radiological Emergency. http://www-pub.iaea .org/MTCD/publications/PubDetails.asp?pubId=7213. Accessed February $11,2011$.

41. Centers for Disease Control and Prevention, Office of Public Health Preparendess and Response. Strategic National Stockpile. http://www.bt.cdc gov/stockpile. Accessed December 31, 2010.

42. Institute of Medicine. Research Priorities in Emergency Preparedness and Response for Public Health Systems: A Letter Report. Washington, DC: National Academies Press; 2008.

43. Institute of Medicine. Assessing Medical Preparedness to Respond to a Terrorist Nuclear Event: Workshop Report. Washington, DC: National Academies Press; 2009.

44. Radiation Studies Branch, Centers for Disease Control and Prevention. Population Monitoring in Radiation Emergencies: A Guide for State and Local Public Health Planners. http://emergency.cdc.gov/radiation/pdf /population-monitoring-guide.pdf. Published August 2007. Accessed February 11, 2011.

45. Skidmore S, Wall W, Church J. Modular Emergency Medical System Concept of Operation for the Acute Care Center: Mass Casualty Strategy for a Biological Terror Incident. http://www.nnemmrs.org/sites/default/files /ECBC_acc_conops_200305.pdf. Published May 2003. Accessed May 2010.

46. Church J. Modular Emergency Medical System. Expanding Local Healthcare Structure in a Mass Casualty Terrorism Event. http://www.nnemmrs .org/sites/default/files/modular_emergency_medical_system_expanding _local_healthcare_structure_in_a_mass_casualty_terrorism_incident .pdf. Published June 1, 2002. Accessed May 1, 2010.

47. Cantrill S, Pons P, Bonnett C, et al. Disaster Alternate Care Facilities: Report and Interactive Tools. AHRQ Publication No. 09-0062. http: //www.ahrq.gov/prep/acfselection/dacfrep.htm. Published October 2009. Accessed February 11, 2011.

48. Pets Evacuation and Transportation Standards Act of 2006 HR 3858. http: //www.govtrack.us/congress/bill.xpd?bill=h109-3858. Accessed August 17, 2010.

49. Bostick NA, Subbarao I, Burkle FM Jr, Hsu EB, Armstrong JH, James JJ. Disaster triage systems for large-scale catastrophic events. Disaster Med Public Health Prep. 2008;2(Suppl 1):S35-S39.

50. Agency for Healthcare Research and Quality. Recommendations for a National Mass Patient and Evacuee Movement, Regulating, and Tracking System. AHRQ Publication No. AHRQ-09-0039-EF. http://www.ahrq .gov/prep/natlsystem. Published 2009. Accessed February 11, 2011.

51. Peleg K, Kellermann AL. Enhancing hospital surge capacity for mass casualty events. JAMA. 2009;302(5):565-567.

52. Hick JL, Hanfling D, Burstein JL, et al. Health care facility and community strategies for patient care surge capacity. Ann Emerg Med. 2004; 44(3):253-261.

53. Agency for Healthcare Research and Quality. Mass Medical Care With Scarce Resources: A Community Planning Guide. AHRQ Publication No. 07-0001. http://www.ahrq.gov/research/mce. Published February 2007. Accessed February 11, 2011.

54. Hick JL, Rubinson L, O'Laughlin DT, Farmer JC. Clinical review: allocating ventilators during large-scale disasters-problems, planning, and process. Crit Care. 2007;11(3):217.

55. Hick JL, Barbera JA, Kelen GD. Refining surge capacity: conventional, contingency, and crisis capacity. Disaster Med Public Health Prep. 2009; 3(2)(Suppl):S59-S67.

56. Caro JJ, DeRenzo EG, Coleman CN, et al. Resource allocation after a nuclear detonation incident: unaltered standards of ethical decision making. Disaster Med Public Health Prep. 2011;5(Suppl 1):S46-S53.

57. Radiation Studies Branch, Centers for Disease Control and Prevention. Roundtable on Hospital Communications in a Mass Casualty Radiological Event. Participants' Comments, Ideas, and Recommendations: A Summary Report. http://www.bt.cdc.gov/radiation/pdf/hospitalroundtablereport .pdf. Published January 14-16, 2003. Accessed February 11, 2011.

58. Hamilton DR, Gavagan TF, Smart KT, et al. Houston's medical disaster response to Hurricane Katrina: part 1: the initial medical response from Trauma Service Area Q. Ann Emerg Med. 2009;53(4):505-514. 
59. Burkle FM Jr, Hsu EB, Loehr M, et al. Definition and functions of health unified command and emergency operations centers for large-scale bioevent disasters within the existing ICS. Disaster Med Public Health Prep. 2007;1(2):135-141.

60. Office of the Assistant Secretary for Preparedness and Response, US Department of Health and Human Services. Hospital Preparedness Program. http://www.phe.gov/Preparedness/planning/hpp/Pages/default.aspx. Accessed May 1, 2010.

61. Hodge JG Jr, Anderson ED, Kirsch TD, et al. Facilitating hospital emergency preparedness: introduction of a model memorandum of understanding. Disaster Med Public Health Prep. 2010;online ahead of print July 19.

62. Barbera JA, Macintyre AG. Medical Surge Capacity and Capability Handbook: A Management System for Integrating Medical and Health Resources During Large-Scale Emergencies. http://www.phe.gov/preparedness /planning/mscc/handbook/pages/default.aspx. Published 2007. Accessed May 15, 2010.

63. Christian MD, Devereaux AV, Dichter JR, Geiling JA, Rubinson L. Definitive care for the critically ill during a disaster: current capabilities and limitations: from a Task Force for Mass Critical Care summit meeting, January 26-27, 2007, Chicago, IL. Chest. 2008;133(5)(Suppl):8S-17S.

64. Devereaux A, Christian MD, Dichter JR, Geiling JA, Rubinson L; Task Force for Mass Critical Care. Summary of suggestions from the task force for mass critical care summit, January 26-27, 2007. Chest. 2008;133(5) (Suppl):1S-7S.

65. Devereaux AV, Dichter JR, Christian MD, et al; Task Force for Mass Critical Care. Definitive care for the critically ill during a disaster: a framework for allocation of scarce resources in mass critical care: from a Task Force for Mass Critical Care summit meeting, January 26-27, 2007, Chicago, IL. Chest. 2008;133(5)(Suppl):51S-66S.

66. Rubinson L, Hick JL, Curtis JR, et al; Task Force for Mass Critical Care. Definitive care for the critically ill during a disaster: medical resources for surge capacity: from a Task Force for Mass Critical Care summit meeting, January 26-27, 2007, Chicago, IL. Chest. 2008;133(5)(Suppl):32S-50S.

67. Rubinson L, Hick JL, Hanfling DG, et al; Task Force for Mass Critical Care. Definitive care for the critically ill during a disaster: a framework for optimizing critical care surge capacity: from a Task Force for Mass Critical Care summit meeting, January 26-27, 2007, Chicago, IL. Chest. 2008; 133(5)(Suppl):18S-31S.

68. Federal Emergency Management Agency, US Department of Homeland Security. National Response Framework. Emergency Support Function \#8Public Health and Medical Services Annex. http://www.fema.gov/pdf /emergency/nrf/nrf-esf-08.pdf. Published January 2008. Accessed May 1, 2010.

69. Federal Emergency Management Agency, US Department of Homeland Security. Multiagency coordination systems. http://www.fema.gov/emergency /nims/MultiagencyCoordinationSystems.shtm. Accessed May 1, 2010.
70. US Fire Administration. Type 3 Incident Management Team (IMT) technical assistance program. http://www.usfa.dhs.gov/fireservice/subjects /incident/imt/index.shtm. Accessed May 1, 2010.

71. Chaffee M. Willingness of health care personnel to work in a disaster: an integrative review of the literature. Disaster Med Public Health Prep. 2009; 3(1):42-56.

72. Becker SM, Middleton SA. Improving hospital preparedness for radiological terrorism: perspectives from emergency department physicians and nurses. Disaster Med Public Health Prep. 2008;2(3):174-184.

73. Lanzilotti SS, Galanis D, Leoni N, Craig B. Hawaii medical professionals assessment. Hawaii Med J. 2002;61(8):162-173.

74. McCabe OL, Barnett DJ, Taylor HG, Links JM. Ready, willing, and able: a framework for improving the public health emergency preparedness system. Disaster Med Public Health Prep. 2010;4(2):161-168.

75. Radiation Injury Treatment Network. Accessed February 14, 2010. http://www.ritn.net.

76. Office of the Assistant Secretary for Preparedness and Response, US Department of Health and Human Services. National Disaster Medical System. http://www.phe.gov/preparedness/responders/ndms/Pages/default.aspx. Accessed February 28, 2011.

77. Tran MD, Garner AA, Morrison I, Sharley PH, Griggs WM, Xavier C. The Bali bombing: civilian aeromedical evacuation. Med J Aust. 2003; 179(7):353-356.

78. Raphael B. When Disaster Strikes: How Individuals and Communities Cope With Catastrophe. New York: Basic Books; 1986.

79. Norwood AE, Ursano RJ, Fullerton CS. Disaster psychiatry: principles and practice. Psychiatr Q. 2000;71(3):207-226.

80. National Center for PTSD. Fact Sheet: phases of traumatic stress reactions in a disaster. http://www.samhsa.gov/dtac/FederalResource/Response /19-Phases_Traumatic_Stress_Reactions_in_Disaster.pdf. Accessed May $1,2010$.

81. Weinberg AD, Kripalani S, McCarthy PL, Schull WJ. Caring for survivors of the Chernobyl disaster. What the clinician should know. JAMA. 1995;274(5):408-412.

82. Focusing on Children in Disasters: Evacuation Planning and Mental Health Recovery. Senate Committee on Homeland Security and Governmental Affairs, Ad Hoc Subcommittee on Disaster Recovery. Testimony of Dr Irwin Redlener, President, Children's Health Fund; August 4, 2009; Washington, DC.

83. Focusing on Children in Disasters: Evacuation Planning and Mental Health Recovery. Senate Committee on Homeland Security and Governmental Affairs, Ad Hoc Subcommittee on Disaster Recovery. Testimony of Rear Admiral Nicole Lurie, Assistant Secretary for Preparedness, US Department of Health and Human Services; August 4, 2009; Washington, DC. 